\title{
Technology Leadership for Secondary Vocational Education Development in China
}

\author{
Xiaoyao Yue ${ }^{1} \quad$ Ping $\mathrm{Xu}^{2 *}$ \\ 1.Graduate school of education, Assumption University, 592/3 Ramkhamheang 24, Bangkok 10240 Thailand \\ 2.International College, Krirk University, No. 3 Soi Ramindra 1, Bangkok 10220, Thailand
}

\begin{abstract}
In the digital age, rapid advancement in technology influence education inherently. This study explored the technology leadership for secondary vocational education development in China. Though content analysis method reviewing critically the research works of china secondary vocational education situation, educational technology development in all of the world and educational leadership theories, the author identify technology leadership including building the technology (or ICT) vision, enhance professional development, transform learning and teaching and evaluate outcomes.
\end{abstract}

Keywords: Technology Leadership, Secondary Vocational Education, Vocational Education Leadership, Classroom Technology, ICT.

DOI: $10.7176 / \mathrm{JEP} / 10-19-08$

Publication date:July $31^{\text {st }} 2019$

\section{Introduction}

High-tech equipment is universal. They are copious using modes and contain games, social medias, company management and education. Undeniably, technology inspire our living, learning and thoughts (Adesope \& Rud, 2019). In the course of history, technology has engraved on education. More than others, computer and internet encroached fundamental structure. Educational technology renders integral probability for developing learning. Teachers and students realize effects of technology. Instructors sway technologies affiliate into classroom (Heinich, Molenda, Russell \& Smaldino, 2002). Indeed, ICT is valuable instrument for facilitate standard learning and teaching. As a activator deep-seated transformation in current schools, ICT is an absolute wheels to prepare students in digital age (Yusuf, 2005). Educational leadership plays a pushing role in technology applied in schools. It is underlying for secondary vocational education overtake new trends of classroom technology.

\section{Literature Review}

\subsection{Technology in Secondary Vocational Education Development in China Context}

2.1.1 Overview of secondary vocational education in China

In china, the secondary vocational education is a basic educational period that the length of schooling is three years. The goal of second vocational education is to cultivate high-quality people who have some degree knowledge and skills of profession. Secondary vocational schools recruit students who are graduates of meddle high school or have the same educational level (Lichan \& Xiaoyun, 2018). In 2015, near 10000 secondary vocational schools are founded and over 18, 000 thousand students in China (Zhijing, 2016).

Chinese vocational education system starts from 1902 of Qing dynasty (Qi, 1995). Both Lin (2015) and Lin (2008) mention, the Chinese secondary vocational education development can be divided into three stages since the establishment of People's Republic of China (PRC). First stage is China develop the vocational education which learn from the Soviet Union and mainly focus on industrial subjects. There are 1701 schools and 635609 students. And 242 industrial subjects of total 348 subjects in 1963. The second stage was established from the Third Plenary Session of the $11^{\text {th }}$ Central Committee (1978) to the 1990s, during the time, the Chinese secondary vocational education subjects refer to 470 subjects that are similar with national vocational education's. The third stage happen is in the $21^{\text {st }}$ century, secondary vocational education curriculum should develop students to meet social professional needs and with life-long learning.

However, Fenghua (2018) argues from 1978 to 2016, secondary vocational education has three major changes. At first, from year 1980 to year 1998, secondary vocational school numbers from 9.7 thousand increase to 22.2 thousand, students' number from 2.2612 million add to 14.6787 million, teacher number from 0.2096 million changes to 0.8553 million. No wonder, the total of secondary educational schools has been decreased because of enrollment expansion of higher education. Students are more likely to go ordinary high schools. From 2002 to 2010, China evaluate secondary vocational education system though reducing numbers of schools and enlarging campus size. Starts from 2010, secondary vocational education becomes weaker. Compare with 2011, there are losing 2200 schools and 0.606 million students in 2016 . By the way, $90 \%$ of secondary vocational students are born in poor families. Government support these students to finish education which shows the social equality. 


\subsubsection{Situation of using technology in secondary vocational education development in China}

China government has published "Interim-long-term educational reform and development plan (2010-2020)", which is for developing ICT in education. Invest computer, multimedia, network in education to address teaching quality and learning efficiency in digital age (Fulan, 2016 \& Chenjingzi, et al. 2015 \& Qi, 2015 \& Xian et al, 2014). China vocational education does build a high-quality digital teaching resource system. Digital teaching resource does not have been used enough when it given for teachers. Teacher are lack of ability and convenience to use digital resource (Bing \& Jing, 2013).

\subsection{Educational technology development in Other Countries \\ 2.2.1 Educational technology development in UK}

Following situations and strategies of integrate digital technologies in UK classroom: Bring Your Own Device (BYOD), it allows student bring mobile phone, laptop, iPad these personal technological devices to study; Eportfolios track learning process of students; flipped classroom requires students preview knowledge before class by online or video; Personal Learning Network-students could study with others in interest online groups; besides, Virtual Learning Environment and Interactive Whiteboards, Software Applications (Apps) and Web 2.0 are also employed (Cambridge, 2017).

\subsubsection{Educational technology development in America}

Since 1990s, America initiates the "one-to-one laptop programs" in K-12 schools. In 2002, the Maine Learning Technology Initiative (MLTI) were applied in classroom for teaching and learning. Teachers use video to transform knowledge, Mobile phone to calculate, medias to teach and ask students read e-books (Zheng et al, 2014 \& Clark, 2010). Many Educational technology are ICT (Information communication technology), for example, Microsoft Word, Excel, PowerPoint, Illustrator, Adobe InDesign, Photoshop, email, video meetings, digital cameras, CD-ROMs, fax machines and so on. They are integrated in curriculum and instruction (Firmin \& Genesi, 2013). In the report of "Teachers Use of Educational Technology development in U.S. Public Schools: 2009", teachers with these technology equipments in daily classroom -includes LCD (liquid crystal display), DLP (digital light processing), interactive whiteboards, and digital cameras.

The National Education Technology Plan (2017) is made by department of education in United States. This plan is based on a national vision, involves the technology improve learning and teaching, and conducts educational researches, educational leaders and teachers in areas, schools, and all levels. Educational leaders should operate these technologies into practices, collaborate with all the stakeholders, such as families, researches and communities, and support learners have attainable resource and tools of technology. Moreover, Culp, Honey and Mandinach (2003) study that technology promotes interaction and communication between teachers and parents, provides information and knowledge sharing and benefit personal learning. From 1983, American government require high school students must learn how to use computer and make it as a graduation requirement.

\subsubsection{Educational technology development in Europe}

In Europe, the teachers have been deep influenced by technology. Educational technology brings safe and reliable in classroom while sometimes is not positive. In fact, students can download assignments from other schools, but raw information online sometimes are wrong. Educational technology facilitates a student-centered teaching (Campo, Vicente \& Miguel, 2012). With setting Digital books, video, 3D system, students could study individually. Classroom alters to much smaller, problem-based learning and collaborative learning are taken in this space. Teachers present content by their mobile phone instead of computer on desk, which implies teacher can catch classroom. Classroom will be in their hand and teachers can teach outside, in everywhere. In the future, classroom will disappear, teachers can teach distance online with virtual classroom and students can perform here. Maybe someday, teachers will disappear while students can learn by themselves in self-study tools. In Lip et al, (2017) study, school compose digital environment to ensure the ability, skills, self-management and information of online learning. Educational leaders supply students the access of online learning and enough devices. Teachers also develop their capacity though digital technology.

\subsubsection{Educational technology development in New Zealand}

The Research New Zealand (2014) summarizes nine aspects of digital technologies in New Zealand education. ICT planning-more than $80 \%$ of schools improve three areas with ICT: teacher professional development, equipment and software upgrades and network infrastructure; as for access and use digital devices $-56 \%$ of principals say over half of students utilize personal technological devices in study; less than $10 \%$ of schools exploit 3D printing and communicate video; $94 \%$ of schools report the students study and play learning game online; $14 \%$ of schools leaders think teachers have skills and ability to manage students in using personal digital devices.

\subsubsection{Educational technology development in Japan}

Recent years, computer supported collaborative learning, free software, commercial software and free web-based material, electric books, smart phone, desk personal computer are key educational technologies applied in 
schools, Japan. In classroom, students sit before their table personal computers with interactive whiteboard (Kodaira \& Watanabe, 2013).

\subsubsection{Educational technology development in Korea}

The Republic of Korea distribute advanced IT infrastructures and Information Communication Technology (ICT) in education. For example, every student has own computer is $58 \%$, schools have 2 mbps speed of internet are 70.7\%. In 2009, 80.0\% schools adapt E-learning (Hwang, 2010 \& Grzybowski, 2013).

2.2.7 Educational technology development in Singapore

In Singapore, ministry of education report that they establish ICT Master Plan to combine ICT with curriculum since from 1997. Singapore K-12 schools add cloud computing to computer science programs. As stimulating collaborative environment, online group learning and working could contact teachers who are not live near even in other countries. Mobile apps also develop for learning. Mobile phone is cheap, timely, and have calculate function. Students and teachers can download mobile apps to share information and knowledge in time. Except, table personal computer with internet and amount of apps can show the related content, videos, and presentation. iBook Author let students write their E-books. Gamification is kind of platform for playing educational game. (Johnson, 2012 \& Zhang, 2006).

\section{Research Methodology}

Content analysis is a summarized method based in the scientific standards (Neuendorf, 2017). Machi and McEvoy (2017) argues content analysis is a systematic procedure to know accurately, read, test, and understand the texts from data and extract information to foster the framework grounding on analyzing the original data. This paper used a content analysis method to explore the technology leadership for secondary vocational education development in China.

The author systematically reviews researches published online in recent years focus on research of educational technology development and leadership for using technology enhance vocational education. The identified key words based on the paper objectives have concerned on leadership could enhance technology in secondary vocational education development in China. Under the theme of research of educational technology development and leadership for using technology enhance vocational education. The data were gathered and summarized responding to the paper objectives. Through analysis, technology leadership include building the technology (or ICT) vision, enhance professional development, transform learning and teaching and evaluate outcomes these four parts

\section{Data Analysis}

4.1 Research of Educational Technology Development

4.1.1 Technology development in education

OECD, (2000) argues the digital technologies includes the hardware, software, and network. The $37 \%$ of the Swedish population access Internet until 1999 as nearly 26\% of Danish population and 10\% of Italian population. At present, using digital technology is growing quickly especially for students in all over the world. It is a long way to try to decrease unbalance in digital devices using and access. Particularly, some of problems are necessary to solve. Such as disability people who cannot recognize, poor regional schools without money to buy digital things, redesign of both hardware and software for women and girls, and ability and skills are not enough for teachers, lack of technical help for parents, more supports needed for students who from poor or language minority places.

Hsu (2007) points out that conversational technologies could be taken advantage in classroom. Conversational technologies have usage of interaction and collaboration, which have been analysis in details. Instant messenger can be installed in classroom for communication; Blogs, learning journals on website, review class researches, online portfolios and wiki are available for collaborative activities in classroom. These conversational technologies boost students create same goal. Podcasts can deliver based knowledge by audio and video for students. Students also do presentation of homework on it. It is apparent that these kinds of conversational technologies play an important role on promoting creation and innovation both in teaching and learning. Moreover, full use of technology collaboratively is more productive than in personal, according to Xiao and Katsipataki (2012). Technology should be used as a supplement to normal teaching than a substitute. They also find educational technology show more effective in mathematics and sciences rather than reading and spelling. It is good for young students to catch up with peers when give them lower technology attaining tutoring class. Over one full day of coaching or continue professional development of teachers will approve of schools introduce technology successfully.

Technology enable students continue, interact and transact learning from this experience. Molecular workbench acquires interaction and visual situation in classroom. Google, Myspace, Facebook these social networking media for students and teachers' communication. Digital games implications in education is rising. Digital game simulation brings about authentic learning practices (Klopfer, et al, 2009). Whereas, quite a few 
confrontations when exploit technologies in classroom. It is easy to see that game is not induce students being aware of deeper knowledge. Simultaneously, teachers are deficient in skills of technology and management when implement technology in courses. For that reason, teachers ought to generate a qualify plan and steps about it.

\section{4,1.2 Classroom technology development}

Teachers mostly make use of online test, email, educational CDs in classroom and other soft types for teaching. Recent research shows ICT use in classroom related to computer experience, gender, aging/teaching experience (Varol, 2013). Teaches spend more time on ICT would acquire more ICT skills. Taleb (2012) suggests ICT have favorable effect in secondary school. ICT will collect knowledge and information, enlarge teacher knowledge, strengthen students do the personal work and learn by themselves. Teachers teach with ICT could increase interaction and offer more resources of content knowledge in the whole room. Nevertheless, computer and online safe and health also have to pay attention. School leaders invite experts to share information about computers and data safety. Students should have basic ability, skills and knowledge of digital technologies to guarantee they can search valid information online.

Interactive whiteboards (IWBs) is one of aspects in classroom technology history. IWB as a tool which can bring both benefits for teachers and students and provide wealth resource. Firmin and Genesi (2013) examines IWB remain students are more engaged and pour attention into study for long competently. The research gains students learn more knowledge from IWB rather than listening in class. Meantime, teacher prepare before, present on class and save their issues promptly. when use it in teaching. Similarly, smart boards thoroughly blend with computers, projectors, smart screens and internet. Smart boards are also worked for classroom. Student are motivated and engaged to learn subjects and teachers are much better on class organization and planning classroom (Akkoyunlua \& Erkan, 2013). Students watch video, search information online and participate discussion. But it is dangerous when students chose smart boards, they might not read books. Sometimes change screen maybe noisy and students cannot hear clear.

4.1.3 Technology enhance teaching and learning outcomes

Educational leaders possess the understanding of global digital age and establish communication, technology, pedagogy, and school system (Snyder, 2005 \& Fisher, 2010). Leader have to assure educational institution and staff could be capable in a digital environment. School will take time to build a digital culture to connect between technology and human dynamics. Leader have to assure educational institution and staff could be capable in a digital environment. School will take time to build a digital culture to connect between technology and human dynamics.

Technology enhance high school teachers teaching in many means such as content resources, teaching materials, thoughts sharing with colleagues, contact with parents and students. And student learning has been impacted by technology. Hence, students use mobile to finish assignments and e-read (Purcell, 2013). If leaders set more practical curriculum in secondary school, likes the media production, the media literacy, media experiences, and identities of outside formal settings, and then permit students have create personal digital videos, these are more significant helpful for student outcomes (Gilje \& Oslo, 2012).

Computers involve student learning in communicate and interactive way. Students study in real time and give digital feedback and evaluation from technologies. Leaders publish policies to blend learning and teaching with technology. For computers advance student engage and student outcomes, schools have to keep every student has least one access for computer. Certain internet speed is suitable for online learning or digital equipment running. Instruction and program accompany by technology could assist students innovate in content knowledge. Yet, technology will influence at-risk students in high schools (Hammond, Zielezinski \& Goldman, 2014). Taking on technology assemble data and facts of at-risk students, researchers can analysis and attain outcomes that advice what school, teacher and parents could do to prevent risk students.

Furthermore, Courville (2011) indicates that technology can be operated in distributed learning and electronic databases. Distributed learning can work out finance and geography troubles and permit students and teachers have more experiences in education. Based learning-likes EPSS (as one of electronic databases) grant teacher receive more new knowledge and beyond-school support resources for professional development. Technology is an important role in interaction and evaluation in teaching, learning and assisting educational training program. Schools will take more advantages from developing technology in education continuously.

In addition, problem-solving skill, collaborative work, and know do to what are key factors students can achieve success in $21^{\text {st }}$ century. Daggett (2010) notes that teachers should know how to use the information that technology bring. Teachers have to be capable facilitators to share knowledge using digital technology; technology support teachers make a better course plan, address interaction in teaching. Teachers encourage student-centered learning, conduct student get correct answer and summary. Educational technologies not only help student answer simple questions; but lead them to deal with complex problems and obtain more $21^{\text {st }}$ century skills to prepare for future life and career. 


\subsubsection{Problems of use technology in classroom}

School promote learning and teaching with develop special participate design and some learning resources. In school technology reform, teacher professional development also has to be pointed that could respond for integrate curriculum with technology together. Integrate online and offline as the prime (Pereira, Ramos \& Marsh, 2016). However, there are some of problems when use technology in education. If teacher do not know the causes and reasons of use technology in course, they would feel exclude in digital policies; and school leaders have different leadership skills may bring effects; lack of money, resource and staff; different student learning backgrounds, abilities, learning styles these issue cases have to take heed (Salavati, 2016). Indeed, the level of teachers accept technology is connected with their attitudes, pedagogical beliefs and experiences. If teachers regard technology with a positive attitude, they will do it better. While teachers do not know how to use technology in classroom, they would feel negative (Zhao \& Frank, 2003).

\subsection{Leadership for Using Technology Enhance Vocational Education 4.2.1 Educational Leadership in Digital Age}

Courville, (2011) promotes educational leaders have to improve student learning outcomes and quality of pedagogy with using technology. Such as "learning-focused envisioning" and "adventurous learning" -school leaders think the quality of student learning should be rely on introducing ICT in schools. And teachers are hoped to do experiments (adventurous learning) though using technology in teaching. Educational leaders must have adequate knowledge, skills of following areas-having educational leadership to build a vision for school; transformation of learning and teaching; advancing student learning outcomes and professional development; supporting, managing and operating; assessing and evaluating outcomes; problem-solving skills and information technologies; social and ethical problem; interaction and communication skills. Still, Klenke, (2007) identifies four areas of leadership competencies of technology for school leaders-make a vision, plan and manage science; staff professional development; support with technology; evaluate and assess methods of outcomes and staff. An excellent technology leader has the competence of interpersonal and communication, the capacity to change school environment, integrate digital technology in classroom, concern on collaborative learning by wikis, online discussion and organizational ability and skill of using technology.

As mentioned above, educational leaders introduce technology in campus to enhance teaching and learning. Commonly, online study is teacher-centered method on the internet; blend leaning is combined traditional learning with virtual learning. School leaders demand to set vision and mission for whole organization; develop school environment, advise student learning and teacher professional development (Lafrance \& Beck, 2013).

In turn, Hennessy (2007) recapitulates school leaders allure high quality teachers and staff with technology skills, foster teacher to continue professional development, erect professional learning center and request excellent coaches to stimulate teachers grasp more related pedagogy and content knowledge. It is Hannafin's (2008) view that school leaders spark a vision for technology growth and manufacture a remarkable plan. This vision has to be processed by administrative teachers, staff who are aware of their own position, role and tasks. School leaders also hold longstanding budgets for launching the plan, propel student computer available and accessed, convince teacher professional development with giving time and property.

4.2.2 Educational Leadership in Vocational Education

Strategic leadership is a Vital ingredient in successful school administration and leadership. Recently, a research of school reform in United States, school principals who hold strategic leadership emerged to acquire crucial enhancements in the largest numeral areas. Principals of school have to improve school performances and simultaneously establish strategic capacity. Strategic leadership define the vision and ethical objectives of a school and interpret them (Ali \& Zulkipli, 2019). Second vocational school leaders with curriculum leadership can be categorized into advocate, navigator, coordinator, consolidator, mentor, caretaker, monitor, and feedback provider. The curriculum school leaders' leadership tasks are classified into building school vision, conducting operation, supporting and incorporating sources, boosting collaboration and communication, guiding program design and teacher

professional development, constructing school culture, resolving performing problems, managing instruction, and improving curriculum assessment (Hsiao, Chen \& Yang, 2008). Falk and Smith (2003), they suggest that vocational education effective leadership should consider the relationship among the internal organizational roles and responsibility, the environment (i.e. Community, Leaders, policy) and the personal contribution. Vocational education leaders adhere to these characteristics: risk-taking, enhancement and innovation behavior; social network, corporation and union building capacities; abilities for future-anticipating hereafter tendency, strategic sourcing, and being proactive.

4.2.3 Educational leadership for technology

School leaders must design and implement effective strategies to help teachers and students identify, understand, and apply technology in the classroom. The grave task nearby is how to integrate this technology effectively with curriculum. There four standards that School principals should have (Papa, 2011): 
- School technology plan revolve around student achievements.

- Link technology plans to school mission and benefits.

- Prevent immoderate point and technical terms

- If realign in curriculum and instructional strategies is implemented, change technology plans.

Flanagan and Jacobsen (2003) explains obstacles to technology integrated are outlined into four areas: pedagogy themes; focus on justice; insufficient professional development; and inadequate informed leadership. Based on the four issues, they define five roles and responsibilities of a school leader:

(1) Learning-leaders have to prove a comprehensive understanding of the ICT Program of learning, particularly of these indicators that refer to unprecedented skills.

(2) Student engagement-school leaders certify fairness of entailment to technology for every student.

(3) Capacity building-school leaders act as positive change agents. Working with staff, supervise the vision for technology application development.

(4) Community-Principals make certain the community involved that include parents and partners to achieve the common goal in technology implementation.

(5) Manage resource-, school leader' responsibilities for resource managing compulsory for technology integration.

In the Anderson and Dexter (2005) report, the concept of school technology leadership was allied to objectives, policies, funds, committee, and other braces of technology for strengthening it work on learning. Their study verifies that technology leadership play a very crucial, determining part in technology outcomes. Eight themes of technology leadership are identified. Technology committee means s school had a ICT or technology committee. Principal days stands school principal spend five or more days on "technology planning, development or management". Principal e-mail school points principals inform regular by e-mail to interactive with not less than two of the following groups: teacher, managerial staff, student, and parent. Staff development policy Principals must put out policy about teacher professional development on technology. School technology budget means educational leaders have to direct technology budget. District support represents that school leader district afford technology spending. Grants means the school receive the grant "over 5\% of the money was expend on technology in three years". Intellectual property policy refers school bring about the policy about "protecting intellectual property rights, such as copyright.

\section{Conclusion and Discussion}

In the 21 st century, to explore leadership could enhance technology in secondary vocational education development in China is far-reaching. Technology leadership include building the technology (or ICT) vision, enhance professional development, transform learning and teaching and evaluate outcomes these four parts (see the Figure 1).

Building the technology (ICT) vision. The school leaders should build technology or ICT vision for the whole organization. They define ethical objectives and make a plan for integrate technology in the campus. Principals must concern on student achievements and prepare them for future. Leaders get ready for economy-longstanding budget for launching the plan. For the whole process, leaders play a role of conducting, supporting, managing and operating.

Enhance professional development. Staff and teacher though professional development programs that could master skills on technology. School leaders have server as a core function of TPD (teacher professional development) with offer time and property. Professional development needs focus on student outcomes and improve teacher's corporation.

Transform learning and teaching. Second vocational leaders have responded to transform learning and teaching by four components. Guarantee students and teachers' technology available and accessed. IWBs (interactive whiteboards), Video, E-books these tools could be integrated in classroom. BYOD (Bring your own device), learning in apps and online teaching these emerging effective methods could be attempted if it possible. Leaders who have abilities to create a learning culture and boost interaction and communication with the technology.

Evaluate outcomes. School principals invest technology aimed at improving student engagement and outcomes. Evaluation and assessments are essential ingredient though check student academic achievements. The technology plan needs to change due to student outcomes. Leaders have capacity to solve problems when it happens. 


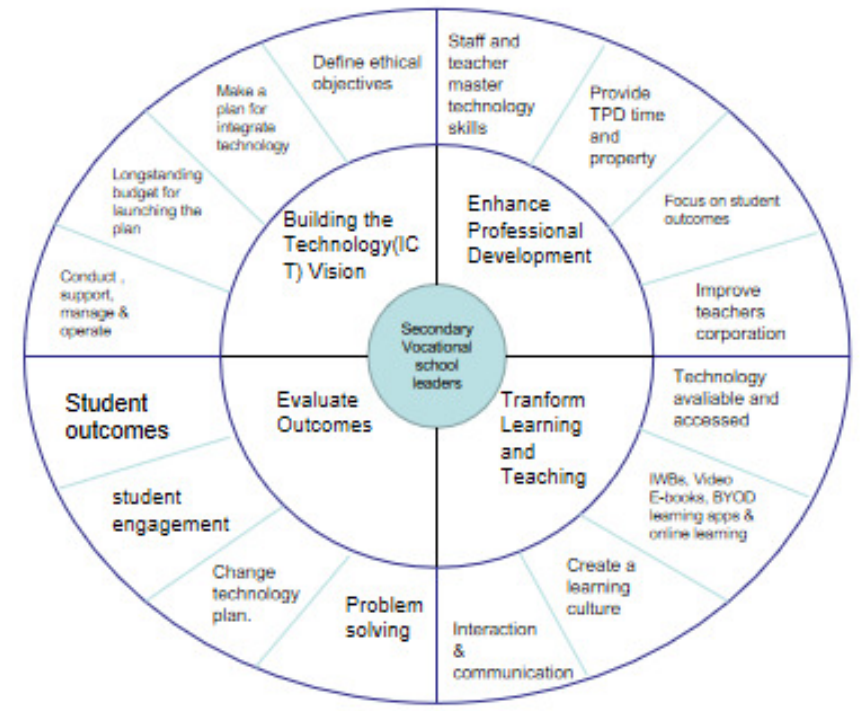

Figure 1: Technology Leadership for Secondary Vocational Education Development in China

\section{Recommendation}

Leadership could enhance technology in secondary vocational education development in China. Technology leadership include building the technology (or ICT) vision, enhance professional development, transform learning and teaching and evaluate outcomes these four parts. Chinese secondary vocational education leaders could set a technology vision, mission for the whole organization. This technology leadership model would be helpful in enhancing school development in digital age. Teachers and staff see the full picture of technology planing from managerial perspective grounding on this leadership model.

\section{References}

Adesope, O. O., \& Rud, A. G. (2019). Contemporary technologies in education: maximizing student engagement, motivation, and learning. Berlin: Springer

Akkoyunlua, B., \& Erkan, S. (2013). A Study on student and teacher views on technology use. Procedia: Social and Behavioral Sciences.

Ali, H. B. M., \& Zulkipli, I. B. (2019). Validating a model of strategic leadership practices for Malaysian vocational college educational leaders: A structural equation modeling approach. European Journal of Training and Development, 43(1/2). PP.21-38.

Anderson and Dexter (2005). School Technology Leadership: An Empirical Investigation of Prevalence and Effect. Educational Administration Quarterly.41(1).PP. 49-82.

Bing, H., \& Jing, G. (2013). The Status Quo of the Construction of Digital Teaching Resource of Vocational Education in China. Theory and practice of education. Vol. 33.

Campo, J., Vicente Negro, V., \& Miguel Núñez, M. (2012). The history of technology education. A comparative study and Forecast. Procedia: Social and Behavioral Sciences.

Chenjingzi, et al. (2015). A Policy Comparison, Development Tendency and Enlightenment of Education Informatization Evaluation. Journal of Distance Education.

Courville, K. (2011). Technology and its use in Education: Present Roles and Future Prospects. Recovery School District Technology Summit.

Culp, K. M. M., Honey. M. \& Mandinach, E. (2003). A Retrospective on Twenty Years of Education Technology Policy. U.S. Department of Education.

Daggett, W.R. (2010). Preparing Students for Their Technological Future. International Center for Leadership in Education.

Falk and Smith (2003). Leadership in vocational education and training: Leadership by design, not by default. Australian National Training Authority.

Firmin, M. W., \& Genesi, D. J. (2013). History and Implementation of Classroom Technology. Procedia - Social and Behavioral Sciences.

Fisher, K. (2010). Technology-enabled active learning environments: an appraisal. OECD.

Flanagan and Jacobsen (2003). Technology leadership for the twenty-first century

principal. Journal of Educational Administration.41 (2). PP. 124-142

Fulan, F. (2016). Empirical Evaluation and Development Strategy Research of ICT in Education in China. Central China Normal University. 
Cambridge Assessment, (2017). Digital technologies in the classroom.

Clark, D. (2010). Transforming America's Education Through Innovation and Technology. The Aspen Institute. vol. 25.

Gilje, O. Ø., \& Oslo, A. H. (2012). Learning Lives Connected: Digital Youth across School and Community Spaces. Comunicar (English edition); Huelva Vol. 20, Iss. 40.

Grzybowski, M. (2013). EDUCATIONAL TECHNOLOGIES IN SOUTH KOREA. General and Professional Education. PP. 3-9.

Hammond, L. D., Zielezinski, M. B., \& Goldman, S. (2014). Using technology to support at-risk students' learning. Stanford center for opportunity police for education.

Hannafin, R. D. (2008). K-12 technology audit: Lessons for school leaders

Heinich, R., Molenda, M., Russell, J. D., \& Smaldino, (2002). Instructional media and technologies for learning (seven edition). New Jersey: Pearson Education.

Hennessy, J.L. (2007). Improving K-12 Education: A Multidisciplinary Initiative at Stanford.

Hua, Z. F. (2018). The forty years of China secondary vocational education development: develop in a repeat way. Chinese Vocational and Technical Education.

Hsu, J. (2007). Innovative Technologies for education and Learning: education and Knowledge-oriented applications of blogs, Wikis, podcasts, and more. International Journal of Information and Communication Technology Education. 3(3).

Hsiao, chen \& Yang, (2008).Leadership of vocational high school principals in curriculum reform: A case study in Taiwan. International Journal of Educational Development. 28. PP.669-686.

Hwang, D. J., Yang, H.K. \& Kim, H. (2010). E-Learning in the Republic of Korea.

UNESCO.

Machi, L. A., \& McEvoy, B., T. (2017). The literature review: Six steps to success. California: SAGE Publication, Inc

Neuendorf, K., A. (2017). The content analysis guidebook. California: SAGE Publication, Inc.

Jing, Y. Z. et al. (2016). From a Country with the Biggest Vocational Education Scale towards a Country with the Most Developed Vocational Education: Research Report of China Vocational Education 2030. Research group of Chinese Vocational and Technical Education Association.

Johnson, et al. (2012). Technology Outlook for Singaporean K-12 Education 2012-2017: An NMC Horizon Project Regional Analysis.

Klenke, K. (2007). Authentic Leadership: A Self, Leader, and Spiritual Identity Perspective. INTERNATIONAL JOURNAL OF LEADERSHIP STUDIES. pp. 68-97.

Klopfer, E. (Ed.). (2009). Using the technology of today, in classroom today: the instruction power of digital games, social networking, simulations, and how teachers can leverage them. The Education Arcade Massachusetts Institute of Technology.

Kodaira. S. I. \& Watanabe, S. (2013). The diversifying media environment of Japanese classrooms and educational content: from the 2012 school broadcast utilization survey. NHK broadcast culture research institute.

Lafrance, J. A. \& Beck, D. (2013). Mapping the Terrain: Educational Leadership Field Experiences in K-12 Virtual Schools. University Council for Educational Administration. NY: SAGE.

Lin, S. (2008). Development and transformation of vocational education in China. Chinese Vocational and Technical Education. Nov.21

Lin, S. \& Ting, X. G. (2015). China secondary vocational education reform and transformation: analysis based on education policy.

Lip, S. (Ed.). (2017). Understanding children's use and experience with digital technologies. Victoria University of Wellington.

Ministry of Education Report. ICT Masterplans in Singapore Education System.

National Education Technology Plan. (2017) U.S. department of education.

OECD, (2000). The Digital Divide within Formal School Education: Causes and Consequences.

Papa, R. (2011). Technology leadership for school improvement. California: Sage

Purcell, et al. (2013). How Teachers Are Using Technology at Home and in Their Classrooms. Pew Research Center's Internet \& American Life Project

Qi, Y. X. (1995). China ancient vocational education history.

Pereira, Í., Ramos, A., \& Marsh, J. (2016).The Digital Literacy and Multimodal Practices of Young Children: Engaging with Emergent Research.

http://digilitey.eu.

Research New Zealand. (2014). Digital technologies in New Zealand schools.

Salavati, S. (2016).Use of Digital Technologies in Education: Complexity of Teachers' Everyday Practice. Linnaeus University Dissertations. 
Snyder, S. (2005). The Digital Culture and Communication: More than just Classroom Learning. Seminar.net: International journal of media, technology and lifelong learning. Vol. 1 - Issue 2.

Taleb, Z. (2012). Information and communication technology skills ranking in

secondary school curriculum. Procedia: Social and Behavioral Sciences.

Xian, L. et al. (2014). Research on the Development Strategy of ICT Infrastructure in Education in the Process of Educational Informatization. Distance Education Journal.

Varol, F. (2013). Element school teachers and teaching with technology. The Turkish Online Journal of Educational technology development, volume 12 issue 3.

Xiao, Z. M., \& Katsipataki, M. (2012). The Impact of Digital Technology on Learning: A Summary for the Education Endowment Foundation. Durham University.

Yusuf, M. O. (2005). Information and communication technology and education: Analysing the Nigerian national policy for information technology. International Education Journal, 6(3), PP.316-321.

Zhang, et al. (2006). Using mobile learning technologies for primary environmental education in Singapore schools. International Science Education Conference.

Zhao, Y. \& Frank, K. A. (2003). Factors affecting technology uses in schools: an ecological perspective. Michigan State University.

Zheng, et al. (2014). History and Implementation of Classroom Technology. Procedia: Social and Behavioral Sciences.

Xiaoyao Yue PhD candidate of educational leadership, Assumption university, Thailand, Aug 2017-now

Publications

International Conference:

- Yue, X.Y. \& Tan, C.C., "A Critical Study of the Nature of and Factors influencing

Student Engagement and Academic and Social Performances: A Mixed Survey-and-Netnography Method" International Multidisciplinary Academic Conference,

Chonburi, Thailand, September 26-30, 2016. (*The extend version was published in

Business Sciences International Research Journal)

- Yue, X.Y., Tan, C.C., \& Jongsureyapart, C., "Person-Situational Field Theory in the Study of Student Engagement to Improve Students' Performance in Academics, Campus Life and Quality of Life: A Comprehensive Pilot-Testing Involving the Students of the School of Management at Mae Fah Luang University", The third Greater Mekong Subregion International Conference (GMSIC), 2016.

- Yue, X. Y. "A study of authentic leadership in transforming higher education in digital age", 2019 Panyapiwat International Conference on Social Science and Management, February 18, 2019.

- Yue, X. Y. "Strategies for the Development of Student Leadership Capacity in Higher Education Institution in China" International Conference on Education, Psychology, and organizational Behavior, Bangkok, Thailand (ICEPO), 2019.

Journal:

- Yue, X.Y. \& Tan, C.C.(2016). A Critical Study of the Nature of and Factors influencing Student Engagement and Academic and Social Performances: A Mixe Survey-and-Netnography Method. Business Sciences International Research Journal, Vol 4(2). ISSN 2321-3191.

Yue, X.Y. (2019). A Study Of Values And Leadership Characteristics Of Educational Leaders Of A Private University In Thailand. Malaysian Journal of Social Sciences and Humanities (MJSSH), Vol 4(2), PP. 4350.

Yue, X.Y. (2019). Exploring Effective Methods of Teacher Professional Development in University for 21st Century Education. International Journal of Innovation and Education Research. Vol 7 (4), PP.248-257.DOI: https://doi.org/10.31686/ijier.Vol7.Iss5.1506

Dr. Ping Full-time Lecturer of International College, Krirk University, Thailand. The major field of study includes educational leadership, educational management, and second-language education. 